\title{
Cross-listings of blockchain-based tokens issued through initial coin offerings: Do liquidity and specific cryptocurrency exchanges matter?
}

\author{
Lennart Ante ${ }^{1,2}$ (D) André Meyer ${ }^{1}$
}

Received: 18 December 2019 / Accepted: 16 February 2021 / Published online: 17 March 2021

(c) The Author(s) 2021

\begin{abstract}
Initial coin offerings (ICOs) represent a novel funding mechanism where digital tokens are issued on the blockchain and sold to investors. One major reason for the success of this financing model is the fact that the issued tokens can immediately be traded on secondary markets. This event study analyzes 250 exchange cross-listings of 135 different tokens issued through ICOs on 22 cryptocurrency exchanges. We find significant abnormal returns of $6.51 \%$ on the listing day and $9.97 \%$ over a seven-day window around the event. Further analysis shows that the results clearly differ for individual cryptocurrency exchanges, as listings on individual exchanges yield returns of up to $34 \%$ on the event day, while others are negligible. An investigation of liquidity-related metrics shows that lower prior trading volume and asset market capitalization have positive effect on listing returns. Investors use phases of high market liquidity to sell off positions around the period of cross-listing events. The results on the cross-listing effects of ICOs may be of relevance to investors/traders, ICO projects, cryptocurrency exchanges and regulators.
\end{abstract}

Keywords Cryptocurrency · Cryptocurrency exchanges · Blockchain · Ethereum · Event study $\cdot$ Token sales

JEL Classification $\mathrm{G} 10 \cdot \mathrm{G} 12 \cdot \mathrm{G} 14$

\section{Introduction}

Initial coin offerings (ICOs) provide ventures with an alternative tool for corporate financing. Many projects have already financed themselves by selling

Lennart Ante

ante@blockchainresearchlab.org

1 Blockchain Research Lab, Max-Brauer-Allee 466, 22765 Hamburg, Germany

2 Faculty of Business Economics \& Social Sciences, University of Hamburg, Von-Melle-Park

5, 20146 Hamburg, Germany 
blockchain-based digital tokens that represent some form of (future) value, and many ICO investors have already made a fortune or total loss. One of the main reasons for the success of ICOs is the fact that tokens can be traded on secondary markets as soon as a cryptocurrency exchange agrees to list them. A special feature of cryptocurrency markets is that there is virtually no order routing through brokers; instead, the assets are traded on a large number of different exchanges, each of which has its own specific characteristics and user base. It is not uncommon for ICO tokens to be successively cross-listed on multiple exchanges, which means that cross-listing events occur more frequently for tokens than for stocks. One speaks of a cross-listing when an asset, which is already tradable on at least one secondary market, is listed on another secondary market-in the case of ICOs tokens cryptocurrency exchanges. Accordingly, cross-listings never represent the first opportunity but a further option to trade an asset.

For stock markets, market segmentation, market liquidity, information disclosure and investor protection have been identified as reasons for cross-listings (Roosenboom and Dijk 2009). Yet stock markets are different from cryptocurrency markets. For example, cryptocurrencies are traded 24/7, and they are but decentralized computer protocol that in theory any exchange can list without the consent of the project itself. Some cryptocurrency exchanges are fully centralized and resemble stock exchanges, while other, decentralized exchanges solely operate as computer code on a blockchain infrastructure, allowing the users to trade peer-to-peer with each other (Warren and Bandeali 2017). The level of regulation and transparency also differs across exchanges. Some of them manipulate or inflate their own markets in order to signal liquidity to potential users and projects and to thereby earn more trading and listing fees (Alameda Research 2019; Bitwise Asset Management 2019).

The effects of cross-listings are a rather new research field for the cryptocurrency sector. To our knowledge, two studies have specifically analyzed such effects, but so far no study has focused solely on ICOs. Benedetti (2019) finds positive listing returns for a sample of 3,625 tokens on 108 exchanges and identifies an increase in trading volume and characteristics like on-blockchain transfer volumes of Ethereumbased tokens. Ante (2019) analyzes 327 cross-listings on 22 exchanges and finds abnormal returns of $5.7 \%$ on the listing day and $9.2 \%$ over a 7 -day event window around the listing. The study also finds significant differences between individual exchanges, as well as evidence of informed trading. For initial listing effects of ICOs, Benedetti and Kostovetsky (2018) find significant underpricing in a sample of ICOs, with abnormal buy-and-hold returns of $48 \%$ within the first 30 trading days, while Momtaz (2019a) finds average underpricing of $8.2 \%$ in ICO campaigns over $\$ 1$ million. Furthermore, Momtaz (2019b) identifies an average abnormal return of $14.8 \%$ on digital currencies within the first trading day after their initial exchange listing. The returns are also driven by key figures like liquidity and market capitalization.

This is the first cross-listing study to focus on ICO tokens. The goal of this article is to provide a fundamental scientific basis for cross-listing effects of ICO tokens. It shall be identified if cross-listings represent positive market (quality) signals, similar to traditional markets, which are expressed by abnormal returns. We aim to explore how ICO tokens perform in exchange cross-listings and whether specific cryptocurrency exchanges or liquidity-related characteristics - in line with signaling theory 
(Spence 1973) — have any effects on listing returns. This can help to better understand the efficiency of ICO token markets and to derive corresponding implications for theory (i.e., academic research) and practice (i.e., crypto market participants). To this end, we subject a data set of 250 listing events of 135 different cryptocurrencies issued through ICOs to an event study of abnormal returns. Potential effects of individual exchanges are tested through sub-samples, and we build regression models of abnormal returns to test for any effects of liquidity metrics.

The ICO phenomenon can be contemplated from various angles, such as the perspective of projects seeking funding (Ante et al. 2018), investors looking for financial return (Fisch \& Momtaz 2020), society benefiting from a new source of finance for start-ups (Fisch et al. 2020), or specific industry players, such as cryptocurrency exchanges (Benedetti 2019). Most of the existing studies assume the perspective of projects, investigating the determinants of success. The present study mostly focuses on the perspective of investors, whom listing returns may afford considerable (shortterm) gains. However, the analysis may also be of interest to all other involved parties: (1) The projects can better understand what investors and the market look for and how to respond to investor expectations; (2) regulators may learn whether specific areas of the market require intervention, for instance if listings are preceded by significant returns, which could indicate market manipulation; (3) cryptocurrency exchanges may be able to identify 'promising' projects to list; and (4) society and regulators can improve their understanding of the market for ICOs and assess its (in) efficiency.

In following section, three hypotheses are derived on the basis of literature. We will provide an overview of cross-listings, where stock markets have received much more research attention than cryptocurrencies and blockchain-based financing such as ICOs. In addition, special characteristics of the market for ICO tokens, cryptocurrency exchanges and liquidity metrics, to which explicit hypotheses refer, are explained. The review of the literature also informs our selection of variables. Section 3 describes the data set and methods while Sect. 4 is dedicated to some descriptive statistics. Section 5 presents the empirical findings, relating first to the general market effects of listing events and then to individual crypto exchanges and market characteristics. Leading up to a brief conclusion, Sect. 6 offers a discussion of the results, some limitations of the paper, implications and avenues for future research.

\section{Related literature and research questions}

\subsection{Exchange (cross-)listings}

The effects of cross-listings have been studied extensively for stock markets. By cross-listing stocks, some companies are able to increase their valuation (Foerster and Karolyi 1999; Miller 1999). The price of stocks and cryptocurrencies rises in anticipation of cross-listings and declines after the events (Ante 2019; Dharan and Ikenberry 1995). According to signaling theory (Spence 1973), projects can show their quality by costly signals. This applies to cross-listings, which require time and resources, often including listing fees. Accordingly, Bris et al. (2007) conclude that 
cross-listings constitute positive quality signals. Stocks tend to experience negative drifts in the days and months following the listing events (Alexander and Janakiramanan 1988; Dharan and Ikenberry 1995; Foerster and Karolyi 1999; Howe and Kelm 1987). However, Miller (1999) and Jayaraman et al.(1993) fail to confirm such affects. For cryptocurrency cross-listings, Ante (2019) shows significant negative CAARs of $-1.5 \%$ over a three-day window after the event.

The literature has identified at least four major reasons to cross-list an asset: (1) market segmentation, (2) liquidity, (3) information disclosure and (4) investor protection (Roosenboom and Dijk 2009), each of which we will discuss in some more detail. First, cross-listings can reduce barriers for international investors and thus reduce market segmentation (Errunza and Losq 1985). Merton (1987) introduces the investor recognition hypothesis, which states that the arrival of new investors reduces the expected returns of existing investors. Motivations to cross-list include exposing the asset to new investors, which may reduce the cost of capital (Baker et al. 2002), and attracting new users or customers for the product (Bancel and Mittoo 2001; Mittoo 1992; Pagano et al. 2002). Ante (2019) suggests that the cryptocurrency exchange market is highly segmented, due to the degree of regulation or organizational differences (e.g., the integration of fiat currencies versus so-called stablecoins that digitally represent fiat currency). Furthermore, liquidity concerns are a major cross-listing motivation. The introduction of new trading markets by means of cross-listings improves liquidity. Trading volume rises with cross-listings both for stocks (Foerster and Karolyi 1999) and cryptocurrencies (Benedetti 2019). Exposing an asset to multiple markets attracts liquidity traders who compete for order flow (Chowdhry and Nanda 1991). Third, information asymmetry refers to the situation where some parties have private information which they may exploit at the expense of others (Miller and Rock 1985). By disclosing additional information, such asymmetry can be reduced. Cantale (1996) suggests that the listing of assets in markets that require more comprehensive disclosure can serve as a signal of quality. Lastly, according to bonding theory (Coffee 2002), firm value increases after listing in a country with stronger investor protection. Results from stock and cryptocurrency markets show that cross-listings have a positive effect on returns in US markets (Doidge et al. 2004; Ante 2019) and elsewhere (Troger 2007), which can be explained by higher or different regulation and thus investor protection.

Given that cross-listings lead to positive abnormal returns for stocks and cryptocurrencies and can therefore be interpreted as a sign of quality, it is reasonable to assume that this is also the case for ICO tokens.

Hypotheses 1 Cross-listings events of ICO tokens represent quality signals that lead to positive abnormal returns.

\subsection{Blockchain-based financing}

Blockchain technology, which enables the secure transmission of value on the Internet, was first introduced as the mechanism underlying the Bitcoin whitepaper (Nakamoto 2008). Tokens are the digital and transferable representation of values 
on blockchains. Start-ups in the blockchain ecosystem have been using token sales since 2013 to raise capital by issuing tokens that provide a specific (future) value to investors. In ICOs, the tokens usually represent currencies or specific values that complement the projects' products or services (e.g., vouchers or software licenses) (Ante et al. 2018). The tokens are usually "minted" by uploading decentralized computer code on a blockchain infrastructure (called smart contracts, or in the special case of tokens: token contracts), like Ethereum. Any type of logic can be programmed into a token contract, including transfer restrictions or inflation. Once uploaded to the blockchain, the code is executed in a decentralized manner and users can transfer the tokens across the network (Ante 2020).

A specific form of ICOs is so-called initial exchange offerings (IEOs), where tokens are directly sold on a crypto exchange. IEOs gained momentum in 2019, offering several advantages over regular ICOs. First, the projects can target the existing and verified user base of an exchange, which promises wider distribution and lower marketing costs, and second, investors know that the token will be tradeable on the exchange after the IEO. Leading exchanges such as Binance that are associated with high cross-listing returns (Ante 2019) may serve as a signal of quality for investors. However, the signaling benefits of IEOs strongly depend on the quality of the selected exchange. There is clearly a risk of asymmetric information and adverse selection, not only between projects and investors but also between exchanges and their users.

Finally, security token offerings (STOs) are a special type of token sale where the tokens represent securities like stocks or bonds. Ante and Fiedler (2020) list various advantages of STOs over traditional securities offerings: Tokens can immediately be transferred and traded 24/7, clearing and settlement processes can be more efficient, custody and brokers can become obsolete and the blockchain infrastructure offers a fully customizable level of transparency. Investors may prefer STOs because the level of investor protection is higher than in ICOs. The authors analyze 151 STOs and found that cheap (to fake) signals, like social media network size or the stated amount of human capital, can promote funding success and can therefore be exploited by the projects.

While there are, as described above, a variety of different forms of blockchainbased token funding, this study refers exclusively to ICOs and not to the specific subgroup of IEOs or the related group of STOs.

\subsubsection{ICO destination markets}

The selected exchange clearly constitutes a crucial characteristic of an ICO. Cryptocurrency exchanges have been associated with market manipulation (Alameda Research 2019; Bitwise Asset Management 2019) and have also been hacked (Ante 2018). Their level of regulatory oversight varies strongly, from comparatively strict regulation (e.g., US-based exchanges like Coinbase or Kraken) to exchanges located in tax havens that lack oversight or amount to nothing more than a blockchain-based computer protocol without an underlying legal entity. A lack of regulation opens the door to several types of moral hazard: (1) misbehavior by the exchanges themselves (e.g., inflating their trading volume), (2) exchange employees using or leaking 
confidential information, i.e., about future token listings, and (3) ICO project teams using insider knowledge about future listings.

Exchanges also differ with respect to their use of fiat currencies. Only some exchanges offer deposits and withdrawals in fiat currencies, while others use socalled stablecoins to mimic fiat currencies. Stablecoins are digital tokens backed by fiat currencies, i.e., a digital dollar is issued for every dollar in a bank account (Ante et al. 2020). On stablecoin exchanges, users can only trade and transfer these digital coins but cannot easily deposit or withdraw them from or to their personal bank account. This represents a market barrier but allows the exchanges to offer fiatlike trading without the need for banking partners. Therefore, ICO projects prefer to be listed on exchanges that offer a fiat gateway. Ante (2019) shows that US-based cryptocurrency exchanges feature higher returns on cross-listings, likely due to their stricter regulation.

The above reasons principally suggest that ICO projects will want to cross-list their token as widely as possible. Yet, firstly, cross-listings usually do not come for free, and secondly, the choice of some exchanges, which may be weakly regulated or prone to manipulation, may indeed be perceived as a negative quality signal by market participants. The size of an exchange should also make a difference. Therefore, we expect that the returns to cross-listing events will differ across the 22 cryptocurrency exchanges in our sample.

Hypotheses 2 Cross-listings lead to effects of varying strength based on the respective cryptocurrency exchanges they take place on.

The goal is to identify whether statistically significant differences are present on the basis of different exchanges. This can be a basis for future investigations, which, e.g., could analyze exchange-specific characteristics, such as regulatory status, jurisdiction or security mechanisms more precisely.

\subsubsection{Liquidity-related characteristics}

Liquidity can be described as the ease of selling an asset. There are various reasons for, or costs of, illiquidity, such as exogenous transaction costs (e.g., trading fees), demand pressure (e.g., availability of buyers and sellers) and counterparty risks (e.g., private information), all of which will have an effect on asset prices (Amihud et al. 2005). Several studies state that to increase liquidity is the primary motivation to cross-list stocks (Fanto and Karmel 1997; Mittoo 1992), and Silva and Chávez (2008) find that cross-listed firms have lower liquidity costs than non-crosslisted firms. For this reason, we also expect to find effects of liquidity on cross-listing returns of ICOs. In the following, various liquidity-related characteristics are discussed.

Market capitalization The first candidate indicator for liquidity is the market capitalization of cryptocurrencies. Data providers like coinmarketcap.com or coingecko.com rank cryptocurrencies based on their market capitalization. Therefore, greater market capitalization affords the projects more attention. Yet market 
capitalization as a metric is problematic as it can be inflated by only distributing a small share of the tokens publicly, while market data providers still calculated the metric based on the full share of tokens. Additionally, implied market capitalization is only relevant if markets are liquid, which many cryptocurrency markets are not.

Trading volume is another potential indicator of the liquidity for cryptocurrencies, but it may likewise be flawed, due to manipulation on the part of the cryptocurrency exchanges (Alameda Research 2019; Bitwise Asset Management 2019). Ante (2019) finds that pre-listing market capitalization and trading volume, as well as the trading volume of the market proxy Bitcoin, affect returns from crosslistings of cryptocurrencies. A high pre-listing trading volume could conceivably reduce listing returns, as the cross-listing will yield less additional liquidity.

Ratio between market capitalization and trading volume Since the trading volume and market capitalization of ICO tokens are not too strongly correlated ( $r=0.67$ in our sample), the ratio of the two metrics might be useful for analysis. That ratio could provide an indication of undervaluation or overvaluation of assets. If an asset with high market capitalization has a low trading volume, this can be interpreted as a sign of illiquidity - the asset is potentially overvalued. On the other hand, it may also simply signal that there are no relevant exchanges on which the asset can be traded. For example, investors may not be willing to purchase tokens at existing exchanges due to investor protection or security concerns. Low market capitalization combined with a high trading volume may indicate an undervalued asset, as the cost of liquidity is low.

Reference market (Bitcoin trading volume and market capitalization) A high trading volume of the reference market Bitcoin can be a signal of general market liquidity, which could affect the returns on cross-listings in two opposite ways. On the one hand, active Bitcoin trading could mean that traders have little attention to spare for a cross-listing. On the other hand, high overall market liquidity could mean a higher inflow into a new trading pair. Bitcoin's market capitalization may in turn serve as a proxy for the size and/or sentiment of the overall market. A high value may signal that cryptocurrency investors have recently achieved higher returns, i.e., that market sentiment is good (a bull market), which may lead to a higher inflow of capital for new cross-listings. However, that sentiment might only apply to Bitcoin, in which case other, newly listed cryptocurrencies will not benefit. Scientific evidence has shown co-jumping effects for Bitcoin and other cryptocurrencies (e.g., Bouri et al. 2020), and Bitcoin is connected to other cryptocurrencies via return shocks ( $\mathrm{Ji}$ et al. 2019). It can therefore be expected that Bitcoin as the largest and most relevant cryptocurrency also has corresponding influences on the ICO tokens under consideration.

Based on the prior explanations, we posit that characteristics such as trading volume and market capitalization, as well as the reference market Bitcoin, have an effect on the returns on ICO cross-listings.

Hypotheses 3 Liquidity-related characteristics represent relevant factors that influence returns from cross-listings of ICO tokens. 
Since there are no comparable studies for cross-listing effects in cryptocurrency markets, this study aims to identify whether liquidity-related characteristics are generally relevant for the development of cross-listing returns. This may in turn provide a basis for future (more specific) investigations. The next section describes the empirical setup we use to test these expectations.

\section{Data and methodology}

\subsection{Sample}

We collected data on listing events of ICO tokens for 22 cryptocurrency exchanges, retaining only ICOs that had at least 31 days of trading history prior to the listing, so that we were able to calculate returns for the 30-day period leading up to the events. This requirement implies that all events are cross-listings, although the exact number of existing secondary markets where a token is already listed is unknown due to a lack of transparency and data availability. The listing events were captured using a Telegram bot (@cryptoeventbot) that connects to exchange APIs and reports new trading pairs, as well as through the cryptocurrency market data provider block.cc, which reports new token listings of cryptocurrency exchanges. In line with McWilliams and Siegel (1997), any events for a given ICO token with overlapping estimation and/or event periods were dropped. This left 250 events referring to 135 tokens. For each event, we collected daily prices, trading volumes and market capitalization both of the token itself and of Bitcoin from coinmarketcap.com for 31 days prior to the exchange listing and 10 days after the event. As cryptocurrency markets operate 24/7, we use daily close prices, which are certain to capture any listing effects on the particular day and are furthermore less likely to be outliers than daily highs or lows.

\subsection{Event study methodology}

We choose a 7-day $(-3,+3)$ event window around the listing day to capture any effects both before and after the listing. Both subperiods will be of interest to cryptocurrency traders, who may try to develop trading strategies based on the results. In line with Ante (2019), who notes that the high volatility of cryptocurrencies means that long estimation periods bear the risk of distorting market returns, we choose a rather short 21-day estimation window $(-30,-10)$. Initially, we use two alternative models to calculate expected returns. First, in the constant mean return model, the expected return of an asset is simply equal to its mean return over the estimation period. Second, the market model represents an extension, as a reference market is additionally used to account for the effects of overall market movements. We use Bitcoin as the reference market, as it accounts for over half of the cryptocurrency market, it trades on all the exchanges covered by the sample, and its price clearly affects other cryptocurrencies (e.g., Burnie 2018; Gkillas et al. 2018; Hu et al. 2019). Therefore, the market model is a safer basis and is used for further analysis in this article. By also (initially) testing the constant mean return model, we can 
draw conclusions about the effect size of the reference market. In summary, the constant mean return model computes results "only" based on the historic asset returns, while the market models excludes potential effects of Bitcoin (i.e., reference market) volatility.

Expected returns are calculated by a time series regression over the prediction period $(-30,-10)$ for every event $i: E R_{i, t}=a_{i}+b_{i} R_{\mathrm{BTC}, t}+e_{i, t}$, where $R_{\mathrm{BTC}, t}$ is the return of the market portfolio. When setting $R_{\mathrm{BTC}, t}$ to 0 , the market model becomes equivalent to the constant mean return model. We calculate abnormal returns as $A R_{i, t}=R_{i, t}-E R_{i, t}$, i.e., as the difference between the actual return $R_{i, t}$ and the expected return $E R_{i, t}$ of an ICO token on day $t$. Cumulative abnormal returns (CAR) are calculated as a sum of the daily ARs across the event window: $C A R_{i}\left(t_{1}, t_{x}\right)=A R_{i, t_{1}}+\ldots+A R_{i, t_{x}}$. Average abnormal returns (AAR) and the cumulative average abnormal return (CAAR) are obtained by averaging these metrics across all events. To test the results for significance, we calculate both $t$-statistics and $z$-statistics (nonparametric Wilcoxon test). In the following, when we speak of a result being significant, this means that both tests, where applicable, are passed at the corresponding level of significance.

\subsection{Independent variables}

To investigate potential effects of specific cryptocurrency exchanges, we introduce a set of 22 dummy variables, one for each destination market (see Table 4 in the appendix for the full list). Furthermore, we test the effects of the following liquidityrelated market characteristics. Asset trading volume (ATV) signifies the log of the average trading volume of a cryptocurrency over the estimation window: $\log \left(\sum_{t-30}^{t-10} \mathrm{x}\right.$ 121) where $\mathrm{x}$ is the asset's trading volume. Bitcoin trading volume (BTV) is calculated analogously. Asset market capitalization (AMC) and Bitcoin market capitalization (BMC) are similarly calculated as the logarithm of the average market capitalization of the respective asset over the 21-day estimation period. Finally, AMC/ATV is an asset's logged average market capitalization over the estimation period divided by its logged average trading volume.

\section{Descriptive statistics}

Figure 1 provides a timeline of ICO start dates and cross-listing events. Most ICOs started in the last three quarters of 2017, while the majority of listing events took place between Q4/17 and Q4/18.

The graph on the left-hand side of Fig. 2 shows the daily raw returns and cumulated returns from 30 days before to 10 days after the cross-listing event. Prior to the event $(-30,-1)$, the average cumulative return amounts to $21.6 \%$ (mean of $0.72 \%$ per day). On the listing day itself $(t=0)$, the average raw return is $7.1 \%$. In the 10-day window after the event, the average cumulative return amounts to $2.6 \%$ 


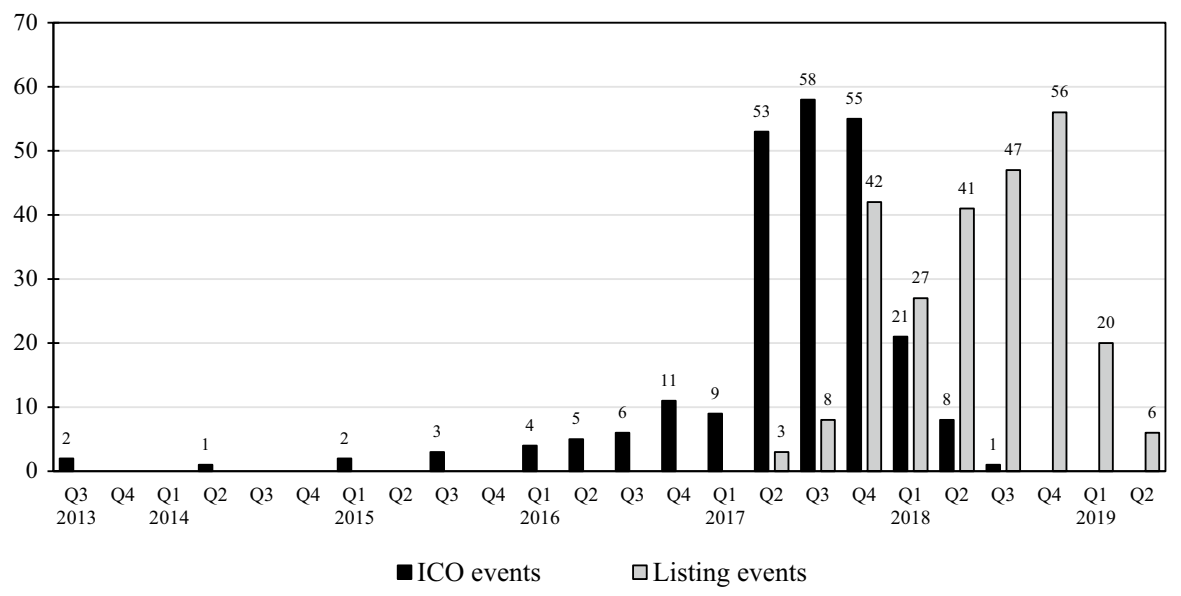

Fig. 1 ICO campaigns and cross-listing events between 2013 and 2019
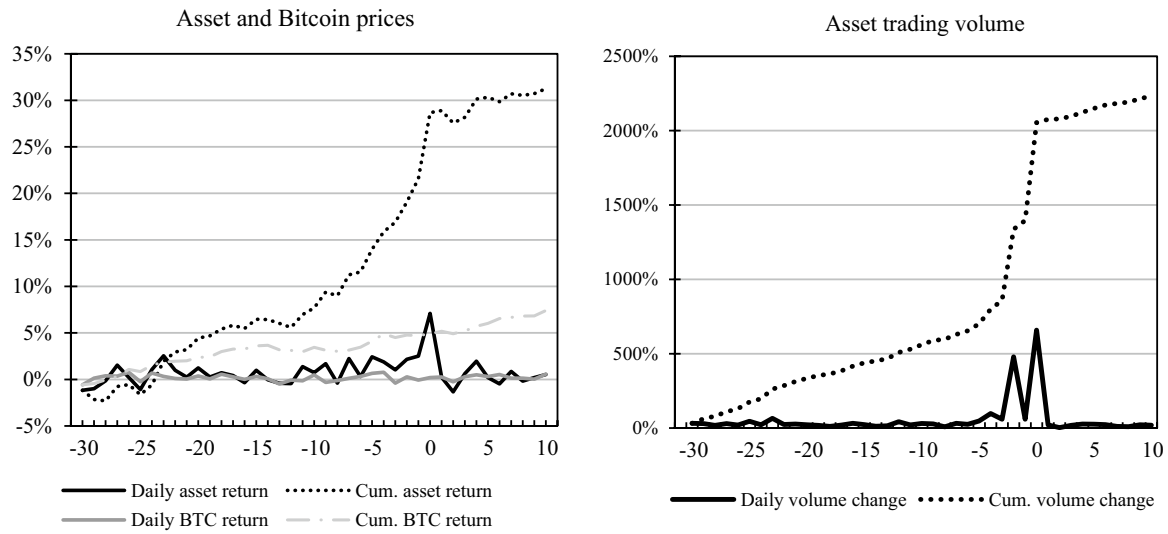

Fig. 2 Average returns and trading volume around cross-listing events

(mean of $0.26 \%$ per day). Over the full period $(-30,+10)$, the tokens experience an average raw return of $31.3 \%$.

The graph on the right-hand side of Fig. 2 shows the daily change in trading volume and the cumulative gains in trading volume over the entire period. The average trading volume for the 250 observations grows continuously over the period $(-30,-1)$ by a total of $1.396 \%$ (mean of $46.5 \%$ per day, the highest individual increase being $478 \%$ in $t=-2$ ) before increasing by another $658 \%$ on average on the listing day. After the listing, the trading volume continues to grow at an average rate of $18 \%$ per day, resulting in a cumulative increase of $180 \%$ over the 10 -day period after the listing. Over the full period $(-30,+10)$, trading volume increases by $2,232 \%$ on average. The Bitcoin price rises fairly steadily over the 250 periods under consideration. This is a first indication that using the market model versus the constant mean return model will produce different results, and it also supports tendency to favor the market model. 
Table 4 in the appendix shows some descriptive statistics on the independent variables, beginning with the 22 dummy variables for the individual exchanges. Accounting for $13 \%$ of the ICO cross-listing events in the data set, Binance takes the lead, followed by FCoin and Bitfinex with $10 \%$ each.

\section{Results}

The presentation of the results is structured as follows. The next subsection is dedicated to results on abnormal returns across all exchanges for various time intervals. We investigate symmetric periods of 7, 5 and 3 days around the event (rows 1-3 in Table 1), individual days from $t=-3$ to $t=3$ (rows $4-10$ ), pre-listing periods that may provide evidence of announcement effects or informed trading (rows 11-16), and post-listing periods (rows 17-22). To identify any significance across intervals and to find the most profitable window, we supplemented the sections with pre- and post-listing windows with event windows that start or end in $t=0$. Next, we present event study results for the 22 crypto exchange sub-samples, though only for the six

Table 1 CAARs around ICO cross-listings

\begin{tabular}{|c|c|c|c|c|c|c|c|c|}
\hline \multirow[t]{2}{*}{ Window } & \multicolumn{4}{|c|}{ (1) Constant mean return model } & \multicolumn{4}{|c|}{ (2) Market model } \\
\hline & CAAR (\%) & $t$-statistic & $z$-statistic & Positive & CAAR $(\%)$ & $t$-statistic & $z$-statistic & Positive \\
\hline-3 to +3 & 9.74 & $3.31 * * *$ & $3.35^{* * * *}$ & 0.56 & 9.97 & $3.60 * * *$ & $4.24 * * *$ & 0.61 \\
\hline-2 to +2 & 8.83 & $3.29 * * *$ & $3.29 * * *$ & 0.58 & 9.12 & $3.50 * * *$ & $4.01 * * *$ & 0.61 \\
\hline-1 to +1 & 8.73 & $3.48 * * *$ & $3.77 * * *$ & 0.58 & 8.70 & $3.34 * * *$ & $4.11 * * *$ & 0.60 \\
\hline-3 & 0.66 & 0.89 & -0.34 & 0.48 & 1.03 & 1.43 & 0.29 & 0.50 \\
\hline-2 & 1.80 & $2.10^{* * *}$ & 1.37 & 0.53 & 1.63 & $1.96^{*}$ & 1.31 & 0.50 \\
\hline-1 & 2.14 & $2.16^{* *}$ & 1.18 & 0.52 & 2.31 & $2.44 * *$ & 1.45 & 0.51 \\
\hline 0 & 6.73 & $2.79 * * *$ & $3.60 * * *$ & 0.59 & 6.51 & $2.69 * * *$ & $2.98 * * *$ & 0.56 \\
\hline+1 & -0.14 & -0.20 & -1.26 & 0.45 & -0.11 & -0.18 & $-1.90 *$ & 0.44 \\
\hline+2 & -1.70 & $-3.15^{* * * *}$ & $-3.62 * * *$ & 0.38 & -1.21 & $-2.34 * *$ & $-3.17 * * *$ & 0.41 \\
\hline+3 & 0.25 & 0.38 & -0.48 & 0.47 & -0.19 & -0.32 & -1.34 & 0.46 \\
\hline-3 to -2 & 2.46 & $2.07 * *$ & 0.99 & 0.52 & 2.66 & $2.34 * *$ & 1.29 & 0.52 \\
\hline-3 to -1 & 4.60 & $3.01 * * *$ & $2.15^{* *}$ & 0.54 & 4.97 & $3.44 * * *$ & $2.79 * * *$ & 0.55 \\
\hline-3 to 0 & 11.33 & $4.10^{* * * *}$ & $4.48 * * *$ & 0.58 & 11.48 & $4.34 * * *$ & $5.22 * * *$ & 0.63 \\
\hline-2 to -1 & 3.94 & $3.12 * * *$ & $2.08 * *$ & 0.52 & 3.94 & $3.25 * * *$ & $2.25 * *$ & 0.53 \\
\hline-2 to 0 & 10.67 & $4.04 * * *$ & $4.60 * * *$ & 0.61 & 10.45 & $4.15^{* * * *}$ & $4.93 * * *$ & 0.61 \\
\hline-1 to 0 & 8.89 & $3.51 * * *$ & $4.17 * * *$ & 0.57 & 8.82 & $3.43 * * *$ & $4.31 * * *$ & 0.58 \\
\hline 0 to +1 & 6.59 & $2.75 * * *$ & $3.11 * * *$ & 0.59 & 6.39 & $2.58 * *$ & $2.60 * * *$ & 0.55 \\
\hline 0 to +2 & 4.89 & $1.98 * *$ & 1.29 & 0.52 & 5.19 & $2.02 * *$ & 1.53 & 0.51 \\
\hline 0 to +3 & 5.14 & $2.01 * *$ & 1.64 & 0.54 & 4.99 & $1.95^{*}$ & 1.40 & 0.53 \\
\hline+1 to +2 & -1.84 & $-2.10 * *$ & $-2.76 * * *$ & 0.44 & -1.32 & -1.63 & $-2.47 * *$ & 0.41 \\
\hline+1 to +3 & -1.59 & -1.37 & $-1.83^{*}$ & 0.44 & -1.51 & -1.49 & $-2.33 * *$ & 0.40 \\
\hline+2 to +3 & -1.45 & $-1.68 *$ & $-2.15^{* *}$ & 0.42 & -1.40 & $1.95 *$ & $-2.40 * *$ & 0.41 \\
\hline
\end{tabular}

$*, * *, * * *$ indicates significance at the $10 \%, 5 \%$ and $1 \%$ level, respectively; 'Positive' means the share of assets with a positive CAR 
windows that serve our main research interests: the full 7 -day window $(-3,+3)$, two pre-listing periods as indicators of informed trading $(-3$ to -2$)$ or announcement effects $(t=-1)$, the event day $(t=0)$, and two post-event windows, $(t=1)$ and $(+2,+3)$. Finally, we estimate the effects of liquidity-related metrics, like trading volumes and market capitalization of ICO tokens and the reference market Bitcoin, on CAARs over the same six periods using regression analysis. To exclude any possibility of hidden time effects, event time is additionally controlled for.

\subsection{Market reaction to ICO token cross-listings}

Table 1 shows CAARs of the 250 cross-listing events over various time windows between -3 and +3 for the constant mean return model (model 1) and the market model (model 2). The two models produce broadly similar effects. We therefore use the market model, which is the more conservative choice, for the analyses we discuss in subsequent sections. The divergence between the results of the two models means that the Bitcoin market has a relevant influence.

A clear picture emerges from the results if we look at how the CAARs change over time. Abnormal returns are achieved especially before and on the listing day, whereas the CAAR is negative for virtually all post-listings windows. Singleday ARs before the events increase from $0.66 \% / 1.03 \%$ (model $1 / 2$ ) at $t=-3$ to $2.14 \% / 2.31 \%$ at $t=-1$, though the results lack significance for at least one test statistic. The abnormal returns peak on the day of the event, where they are also highly significant, at $6.73 \% / 6.51 \%$, with $56 \% / 59 \%$ of the events producing positive ARs. While the results for the day after the event, at $-0.14 \% /-0.11 \%$, are mostly insignificant, the results for the second day after the event are highly significant and show negative CAARs of $-1.70 \% /-2.34 \%$. Furthermore, the proportion of negative results reaches $62 \% / 59 \%$. For the full event window $(-3,+3)$, model 1 returns a CAAR of $9.74 \%$ (56\% positive) and model 2 of $9.97 \%$ (61\% positive), both of which are significant at the $1 \%$-level for both test statistics. Similar results are obtained using five-day $(8.83 \%)$ and three-day event windows $(8.73 \%)$ around the listing day.

The four-day window that ends at the event $(-3,0)$ shows the highest CAARs, at $11.33 \% / 11.48 \%$ - clearly higher that the results for the full event window of seven days. Furthermore, these results are significant at the $1 \%$ level for both test statistics. The windows with the highest shares of positive CARs are $(-2,0)$ according to model $1(61 \%)$ and $(-3,0)$ according to model $2(63 \%)$. During the three-day period leading up to the event $(-3,-1)$, ICO tokens experience an abnormal price increase of $4.97 \%(p<0.01)$ in model 2 . The results are similar but less significant according to the constant mean return model. The period $(-2,-1)$ has a significant CAAR of $3.94 \%$ for both models. We find negative CAARs for most days and windows that start in $t=1$ or $\mathrm{t}=2$ report more than $50 \%$ negative events. The second day after the event has a significant CAAR of $-1.7 \% /-1.21 \%$. For days two and three after the event $(+2,+3)$, we find a significant CAAR of $-1.45 \% /-1.4 \%$. 


\subsection{Destination market results}

Table 2 presents results for the individual cryptocurrency exchanges for the six time windows mentioned above. For the full event window, only Binance $(20.3 \%)$, Bithumb (9.9\%), Bittrex (39.5\%) and OKEx (16.4\%) feature significant and positive results. Seven of the 22 trading venues have a majority of negative events across the full event window; only five exchanges have negative (though insignificant) CAARs.

In the $(-3,-2)$ window, only cross-listings on the Korean-based exchange Bithumb $(7.7 \% ; p<0.1)$ show a significant return. Overall, 16 of the 22 exchanges have positive CAARs for this period. One day before the listing events, the CAARs are positive for 14 of the 22 exchanges; on the listing day, 13 of the exchanges show positive CAARs; on the day after the listing, only half of the exchanges do so, and even fewer in the window $(+2,+3)$. On the day before the listing, the three exchanges Bitfinex (5.8\%; $p<0.05)$, Huobi $(7.1 \% ; p<0.01)$ and Bithumb $(4.2 \%$; $p<0.1$ ) show positive CAARs that are significant in terms of both statistics, while on the listing days themselves, eight exchanges exhibit significant results for at least one statistic. Bittrex has the highest CAAR (34\%), followed by Bitfinex (27.7\%). However, the results for both exchanges are only significant regarding the $z$-statistic, while Binance shows a positive CAAR of $16.3 \%$ that is significant at the $1 \%$-level for both statistics. Bithumb has a positive CAAR of 5.5\% $(p<0.05)$, in contrast to Bibox and Bitforex, which both show negative CAARs (4.7\%/4.6\%). Gate.io also has a negative CAAR of $6.2 \%(p<0.1)$. While the number of exchanges with negative CAARs increases after the listing events, we find fewer significant results. On the day after the listings, the results of both Huobi $(-4.1 \%)$ and Upbit $(-3.3 \%)$ are significant for both statistics at least at the 5\% level. The three exchanges Binance $(-6.8 \% ; p<0.01)$, Bithumb $(-5.4 \% ; p<0.05)$ and KuCoin $(-4.3 \% ; p<0.05)$ have significant negative results for the event window $(+2,+3)$.

\subsection{Liquidity-related effects}

Table 3 shows the results of regressing, by OLS, the CAARs obtained from the market model on various liquidity metrics and time control variables (year dummies) for the same six periods as above. Figure 3in the appendix shows plots of the CAAR distribution for each of the six periods. Effects that are time-specific and do not belong to the liquidity metric are thus accounted for. For each of the 30 regressions, the table shows the estimation coefficient and the heteroskedasticity-robust standard error for the liquidity variable, as well as the coefficient of determination $\left(\mathrm{R}^{2}\right)$. Data on asset market capitalization were not available for all observations, which somewhat reduces the usable sample. For descriptive statistics on the liquidity metrics, see Table 4 in the appendix.

For asset trading volume, we find significant negative effects for the full event window and for the event day, with $R^{2}$-values of $11.6 \%(p<0.01)$ and $7.4 \%$ $(p<0.05)$, respectively. This shows that asset trading volume has a negative effect on listing returns, with most of that effect taking place on the day of the event. We find the same fundamental and significant negative relationship between asset 


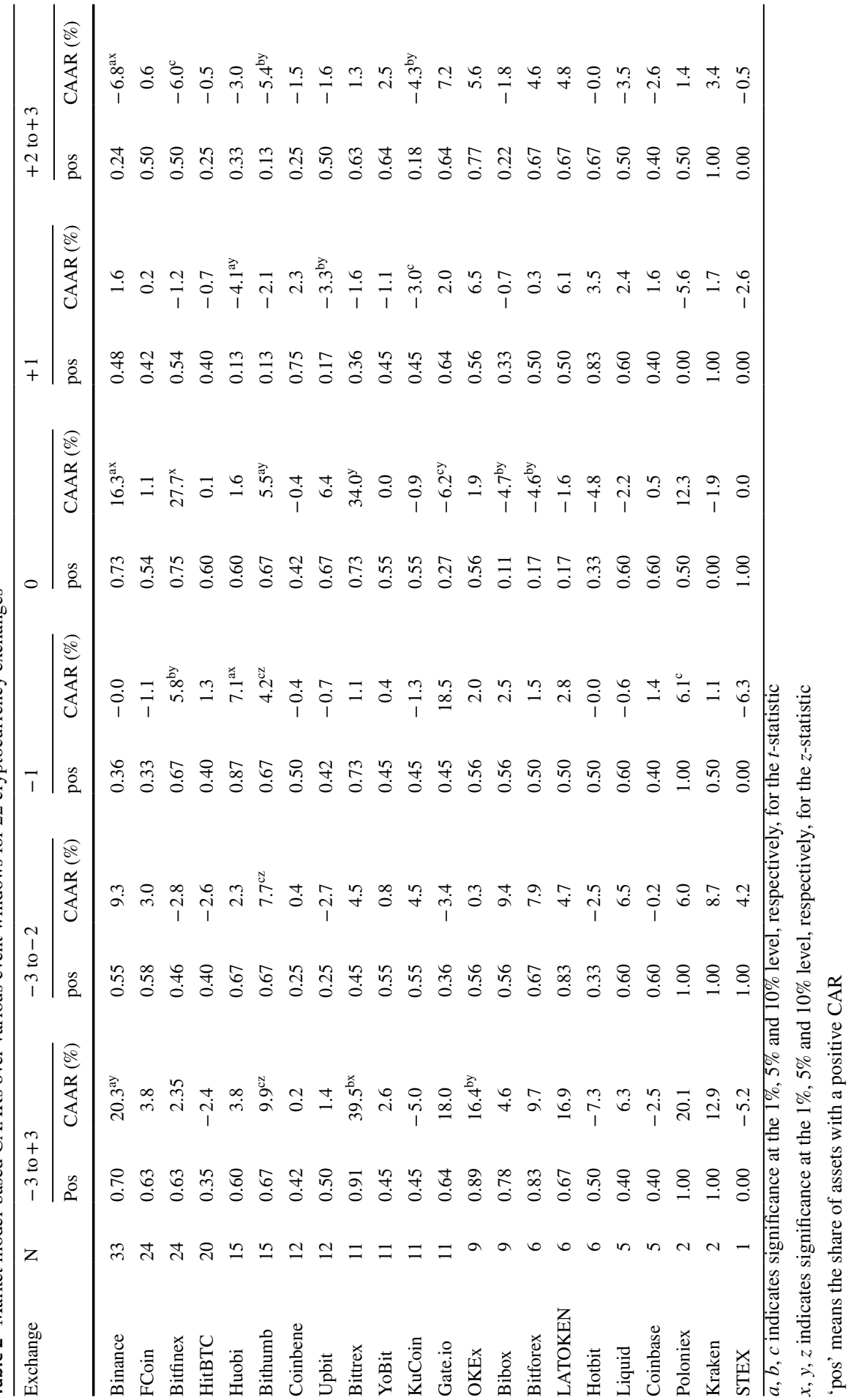




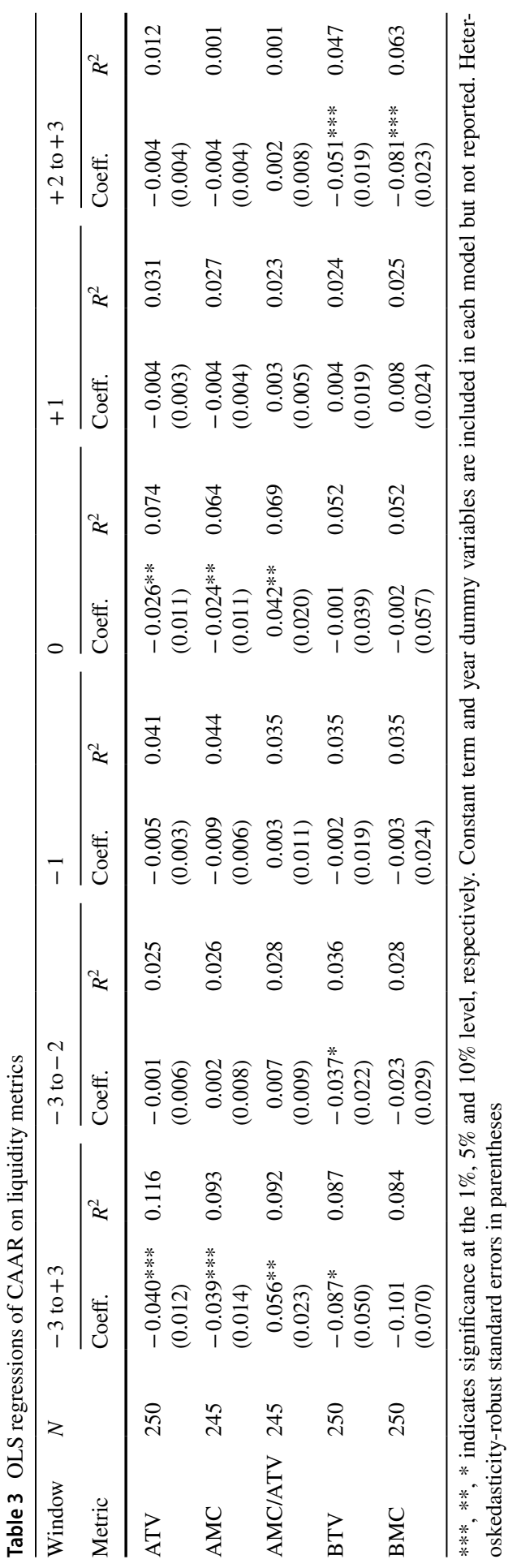


market capitalization and the CAAR for those two periods. However, these models have lower explanatory power $(9.3 \% / 6.4 \%)$, which suggests that trading volume is the more relevant metric. As explained above, the ratio of asset market capitalization to asset trading volume (AMC/ATV) permits conclusions about potential overvaluation or undervaluation. We find positive and significant effects both for the $(-3,+3)$ window $(0.056, p<0.05)$ and for the event day $(0.042 ; p<0.05)$.

Besides asset-specific metrics, we also test for any influence of the overall market, which we proxy by Bitcoin. Bitcoin trading volume (BTV) has a significant negative effect across the full event window. Unlike with the previous asset metrics, however, this effect is not attributable to the day of the event or the day before or after, but rather to the $(-3,-2)$ period $(-0.037 ; p<0.1)$ and the $(+2,+3)$ period $(-0.051$; $p<0.01$ ). For Bitcoin market capitalization (BMC), we identify a highly significant negative effect for $(+3,+2)$ as the only relevant effect.

\section{Discussion}

One primary goal of this study is to gain a basic understanding of whether ICO token cross-listings represent-similar to cross-listings of other assets, such as socks - positive market signals that result in abnormal returns. Regardless of the duration of the event windows or the choice of the constant mean return model versus the market model, cross-listing events produce excess returns for cryptocurrencies issued through ICOs. We thus accept Hypotheses 1. For 3-, 5-, and 7-day windows around the listing events, we identify positive and highly significant CAARs, which increase with the length of the event window. The positive effects of cross-listing events match the outcome of prior literature on cryptocurrency cross-listings (Ante 2019), as well as the stock market literature (Foerster and Karolyi 1999; Miller 1999). While Ante (2019) identified CAARs of $5.7 \%$ for $t=0$ and $9.2 \%$ for $(-3,+3)$ for cryptocurrency cross-listings, we find CAARs of $6.51 \%$ for the listing day and $9.97 \%$ for the full event window, which suggests that markets for ICOs are even less efficient than cryptocurrencies in general. This confirms that cross-listing events are mostly positive news for ICO tokens that lead to positive price corrections in the short term.

The positive returns suggest that ICO projects can use cross-listings to signal their quality to the market. Similar results apply to cross-listings of stocks (Bris et al. 2007). In line with signaling theory (Spence 1973), a cross-listing is a costly signal, requiring coordination, listing fees or disclosure of information. A cross-listing may afford renewed recognition to projects with little liquidity, which were perhaps already considered a failure. Accordingly, an implication of this study is that ICO projects should constantly work to list their tokens at new exchanges. This will lead to abnormal returns, which can satisfy the existing investor base and attract new investors or token users. However, given that we consider abnormal returns only until three days after the cross-listing, we cannot say what the longer-term effects are.

The positive impact of the cross-listing events may be explained by the reduction of investment barriers or new investors from other jurisdictions, but also the projects' increased visibility (Ante 2019; Baker et al. 2002; Errunza and Losq 1985). 
In line with the investor recognition hypothesis (Merton 1987), cryptocurrency projects may seek to attract new investors in order to reduce the expected returns of existing investors. Although the expected returns do not actually decline, the additional demand from new users allows existing investors to realize profits. Even the projects themselves, which usually retain a portion of their tokens, gain an additional opportunity to sell those tokens and thus to obtain cheaper finance. Jayaraman et al. (1993) make an analogous argument for stock market cross-listings.

We find significant negative CAARs of $-1.4 \%$ for the post-listing period $(+2,+3)$. A closer look at the individual days after the listing events shows that this effect is especially attributable to day two, with a significant negative AAR of $-1.21 \%$. These results are in line with the literature on stocks (Foerster and Karolyi 1999; Howe and Kelm 1987) and cryptocurrencies (Ante 2019) and suggest that existing investors use the increased liquidity of cross-listing events to sell all or part of their holdings, and this increased supply overcompensates the demand from new traders.

While positive listing announcement effects have been identified for stock markets (e.g., Miller 1999; Roosenboom and Dijk 2009), we in turn find a highly significant CAAR of $4.97 \%$ over the three pre-listing days, which suggests that the markets knew about the upcoming listing events beforehand and adjusted the prices accordingly. Ante (2019) even finds a significant positive AAR of $6 \%$ on the day before the announcements, pointing to the possibility that exchanges that pre-announce listings leak information. We similarly identify positive returns of $2.66 \%$ for the $(-3,-2)$ window that indicate that these effects cannot only be explained by announcements (as they are only in $t=-1$ or $t=0$ in our sample) but that private information leaks into the market and triggers informed trading. Based on the findings, two implications can be derived for cryptocurrency exchanges. On the one hand, it may be worthwhile to cross-list ICO tokens, since the corresponding abnormal price effect shows that investor interest exists despite already existing market access. However, primary listings potentially may lead to even higher interest and initial returns - this study cannot answer this question. The second implication is that information about upcoming listings should be better secured to protect uninformed investors from exploitation by informed traders. This does not only apply to exchanges but is also relevant for the supervisory authorities, which should create legal certainty, i.e., regulation, and ultimately investigate violations.

We also accept Hypotheses 2, as effects of cross-listings differ significantly across the 22 cryptocurrency exchanges we examined. Only four exchanges deliver significant positive results for the full event window, while five exchanges yield negative results. We find evidence of unloading effects in the form of significant negative abnormal returns after the cross-listings, though to varying degrees for the individual exchanges. In fact, we do not find any significant positive effects after the event day. It therefore appears that owners of ICO tokens, i.e., investors, should sell their tokens no later than the day of the listing, and potential buyers should refrain from a hasty purchase but wait at least for three days. This provides a starting point for future studies of longer ex-post periods, since it is quite conceivable that effects will continue to flatten out or possibly even reverse.

Another interesting fact is that Bittrex, which was based in the US when the cross-listing events took place (now legally based in Liechtenstein), achieved the 
highest CAAR of the sample. The US are generally considered to offer good investor protection. The success of projects cross-listed on Bittrex is consistent with bonding theory (Coffee 1999, 2002), which suggests that firms from countries with weaker investor protection can increase their valuation by cross-listing in countries with stronger securities regulation. This finding indicates that projects may have an incentive to list their tokens on more tightly regulated exchanges in order to signal quality and legal certainty.

Regarding liquidity-related characteristics, we identify significant effects for all of the five selected metrics. We therefore accept Hypotheses 3. High market capitalization and high trading volumes, i.e., by implication high liquidity, of ICO tokens have negative effects on returns. Clearly previously illiquid assets benefit more from a cross-listing, as expected. Market capitalization or trading volume may correlate with the number of exchanges on which the asset is already tradable. Listing an asset on an additional exchange will then only have marginal effects. These results on the market capitalization of ICO tokens may indicate that projects may initially sell their tokens at a lower value, resulting in a low valuation. With new markets, this valuation increases and market liquidity increases. This would confirm the market liquidity hypothesis (Aggarwal et al. 2002).

It seems conceivable that the trading volume of tokens with lower prior volume increases more strongly with cross-listings. The effects are greater for smaller projects, which may be due for example to reduced cost of capital (Baker et al. 2002), new customers (Bancel and Mittoo 2001; Mittoo 1992; Pagano et al. 2002) or bonding (Ante 2019; Doidge et al. 2004). The investigation of the ratio between the two metrics of token liquidity confirms this effect. A high ratio of market capitalization to trading volume has a positive effect on cross-listing returns.

The analysis of the overall market, i.e., by using Bitcoin as a proxy, permits some conclusions regarding the effects of market liquidity and market sentiment. We identify a negative effect of Bitcoin's trading volume, which may indicate that in times of high market liquidity, cross-listings receive less attention. The bulk of these effects occurs in $(-3,-2)$ and in $(+2,+3)$, which indicates that high market liquidity is used for unloading. Existing investors may use pre-listing phases to enter positions and the post-listing phase to liquidate their positions, as suggested by the literature on cross-listings (Foerster and Karolyi 1999; Howe and Kelm 1987). With regard to Bitcoin's market capitalization, we only find a significant negative effect for the post-listing window $(+2,+3)$. As with Bitcoin trading volume, this may indicate that positive overall market sentiment encourages existing investors to liquidate their positions and harvest the profits. In principle, reverse causality is also conceivable: The sale of tokens causes an increase in Bitcoin trading volume. However, any such effects are likely to be minimal, given the relative sizes of the assets involved.

Accordingly, the market history of ICO tokens provides a basis for investors or traders to assess the potential effects of cross-listings and formulate potential investment strategies. In addition, the consideration of liquidity-related characteristics provides a basis for cryptocurrency exchanges to identify promising ICO tokens or to optimize the timing of cross-listings. The implication of optimization of cross-listing timing also applies to ICO projects, which are, however, dependent on exchanges and therefore only have limited influence. 


\section{Limitations and future research}

Being among the first in its field, this study is subject to several limitations. Firstly, sample size: Since the cryptocurrency market is still relatively young, the number of ICOs and associated cross-listing events is limited. We have been unable to identify and record all ICO cross-listing events during the selected period, and furthermore had to exclude a large number of cross-listings that took place in overlapping time intervals. We use market data from coinmarketcap.com, which covers the most important exchanges but misses others. Our data set of 250 observations generally suffices for analyses, yet some of the sub-samples for individual exchanges are on the small side. A larger sample would be useful to confirm our findings.

Secondly, the number of exchanges on which the projects previously traded may also affect the abnormal returns of cross-listing event, as it does in stock markets (You et al. 2013). Since we were unable to obtain this information, there is a risk of omitted variable bias. If such data could be collected ex-post, it would be interesting to test the hypothesis of the 'decreasing marginal utility of cross-listings', i.e., whether projects that are already listed on a number of exchanges benefit less from yet another cross-listing. Thirdly, event studies in the stock market literature often use various other asset pricing models or significantly longer estimation windows. Applying these methods to the cryptocurrency market required us to rely on a much shorter prediction window and comparatively simple asset pricing models.

The very limited literature on cross-listings of cryptocurrencies or ICOs and the simultaneous wealth of analogous studies on traditional financial markets suggest a number of avenues for future research. First, while we chose an event window of seven days and daily prices, future studies may consider completely different periods and time intervals. Our results essentially show that the wider the window, the higher the abnormal return: $6.51 \%$ for $t=0,8.7 \%$ for $(-1,+1), 9.12 \%$ for $(-2,+2)$ and $9.97 \%$ for $(-3,+3)$. This begs the question as to how far this trend may continue. Also, the positive AAR of the event day overcompensates the negative CAAR of the post-listing period $(+1,+3)$. Future research might ascertain whether listing events also have a long-term positive effect.

Second, while we have provided some evidence on how cross-listing effects differ between exchanges, the explanation these differences must be left for future research. Possible determinants include the transparency of an exchange, overall liquidity, access to derivatives, fiat deposits and withdrawals, and location. It will be interesting to see whether the returns depend more on the reputation of the exchanges or on their fundamental properties. A related question is whether the differences in returns are even attributable to the exchanges themselves or rather to the projects that select these exchanges for cross-listing.

Third, seven of the seventeen exchanges that have a positive but insignificant CAAR over the full event window could be called pre-event gainers, in that most of their effects accrue before the actual event. On these exchanges and the four significant ones, information about the cross-listing appears to have found its way into the prices before the event itself. However, since we do not know when the cross-listings were announced, we are unable to identify any information leakage and potentially informed trading. 
Fourth, excess cash holdings of cross-listed companies are valued more highly than those of companies listed on a single stock exchange (Frésard and Salva 2010). The market can often monitor the amount of cryptocurrency collected, as the blockchain technology provides a transparent view of all assets based on it. Future investigations could analyze the relationship between excessive cash holdings and project valuation. Fifth, projects often retain some of their own cryptocurrency to benefit from future appreciation. By monitoring the blockchain and addresses with these specific tokens, it should be possible to determine if team tokens are transferred immediately before the announcement of new cross-listings.

Sixth, future research could investigate to what extent abnormal returns surrounding cross-listings depend on information about the project that was already available at the time of the ICO and on the basis of which investors assess the quality of a project, including human capital, business model quality, business plans or whitepapers, funding goals and a variety of other metrics (Ante et al. 2018). For example, it may be possible to identify whether tax haven-based projects are more likely to experience abnormal returns before the announcement of cross-listings (informed trading) or whether the proportion of tokens retained by the team has an effect on cross-listings.

Classic key figures from stock markets, such as the price-to-earnings ratio, can only be applied to the cryptocurrency market to a very limited extent, if at all. Possibly relevant metrics could, however, be generated on the basis of the corresponding number of (active) users of a token (e.g., Metcalfe's Law) or the token's transaction activity (NVT ratio; the market capitalization in USD divided by the daily volume (in USD) that is transmitted on the blockchain) on the blockchain. Decentralized computer protocol probably requires special metrics, which in turn could explain returns from cross-listings.

\section{Conclusion}

This event study has analyzed price effects of cross-listings of cryptocurrency issued through ICOs. The sample comprises 250 listing events of 135 individual ICOs. On the day of the cross-listing, we found abnormal returns between $6.51 \%$ and $6.73 \%$, depending on whether the model for expected returns includes Bitcoin as the reference market. Across a 7-day window from three days before to three days after the event, the abnormal returns amount to almost ten percent. Thus, cross-listings are generally positive events for ICO tokens, as they represent costly signals of quality to the market. Furthermore, we found that the abnormal returns also depend on the exchanges on which the listings take place, as well as on liquidity-related metrics. Of the 22 individual exchanges analyzed, four had positive significant effects over the 7-day period. An asset's prior liquidity, in the form of market capitalization and trading volume, has negative effects on listing returns.

The results extend the existing literature on cross-listings to ICO tokens, showing that the returns from such events systematically depend on measurable factors. The effects are generally comparable to those in stock markets, but much stronger. This indicates that the markets for ICO tokens are comparatively inefficient. The results can help traders form their strategies, assist projects in selecting appropriate 
exchanges, help exchanges select projects and time cross-listings, and provide regulators and society with in-depth insights into the ICO market. The results may also inspire a wide range of future research approaches that can bring more transparency to this still under-researched and opaque market.

\section{Appendix}

See Table 4 and Fig. 3.

Table 4 Descriptive statistics

\begin{tabular}{lcrllll}
\hline Variable & $N$ & Mean & SD & Median & Min. & Max. \\
\hline Binance & 250 & 0.13 & - & 0 & 0 & 1 \\
FCoin & 250 & 0.10 & - & 0 & 0 & 1 \\
Bitfinex & 250 & 0.10 & - & 0 & 0 & 1 \\
HitBTC & 250 & 0.08 & - & 0 & 0 & 1 \\
Huobi & 250 & 0.06 & - & 0 & 0 & 1 \\
Bithumb & 250 & 0.06 & - & 0 & 0 & 1 \\
Coinbene & 250 & 0.05 & - & 0 & 0 & 1 \\
Upbit & 250 & 0.05 & - & 0 & 0 & 1 \\
Bittrex & 250 & 0.04 & - & 0 & 0 & 1 \\
YoBit & 250 & 0.04 & - & 0 & 0 & 1 \\
KuCoin & 250 & 0.04 & - & 0 & 0 & 1 \\
Gate.io & 250 & 0.04 & - & 0 & 0 & 1 \\
OKEx & 250 & 0.04 & - & 0 & 0 & 1 \\
Bibox & 250 & 0.04 & - & 0 & 0 & 1 \\
Bitforex & 250 & 0.02 & - & 0 & 0 & 1 \\
LATOKEN & 250 & 0.02 & - & 0 & 0 & 1 \\
Hotbit & 250 & 0.02 & - & 0 & 0 & 1 \\
Liquid & 250 & 0.02 & - & 0 & 0 & 1 \\
Coinbase & 250 & 0.02 & - & 0 & 0 & 1 \\
Poloniex & 250 & 0.01 & - & 0 & 0 & 1 \\
Kraken & 250 & 0.01 & - & 0 & 0 & 1 \\
STEX & 250 & 0.00 & - & 0 & 0 & 1 \\
ATV & 250 & 15.05 & 2.22 & 15.08 & 8.12 & 20.64 \\
AMC & 245 & 18.33 & 1.77 & 18.34 & 14.14 & 22.70 \\
AMC/ATV & 245 & 3.24 & 1.21 & 3.16 & 0.27 & 7.82 \\
BTV & 250 & 22.35 & 0.58 & 22.29 & 19.60 & 24.00 \\
BMC & 250 & 25.45 & 0.42 & 25.46 & 23.66 & 26.33 \\
\hline & & & & & &
\end{tabular}



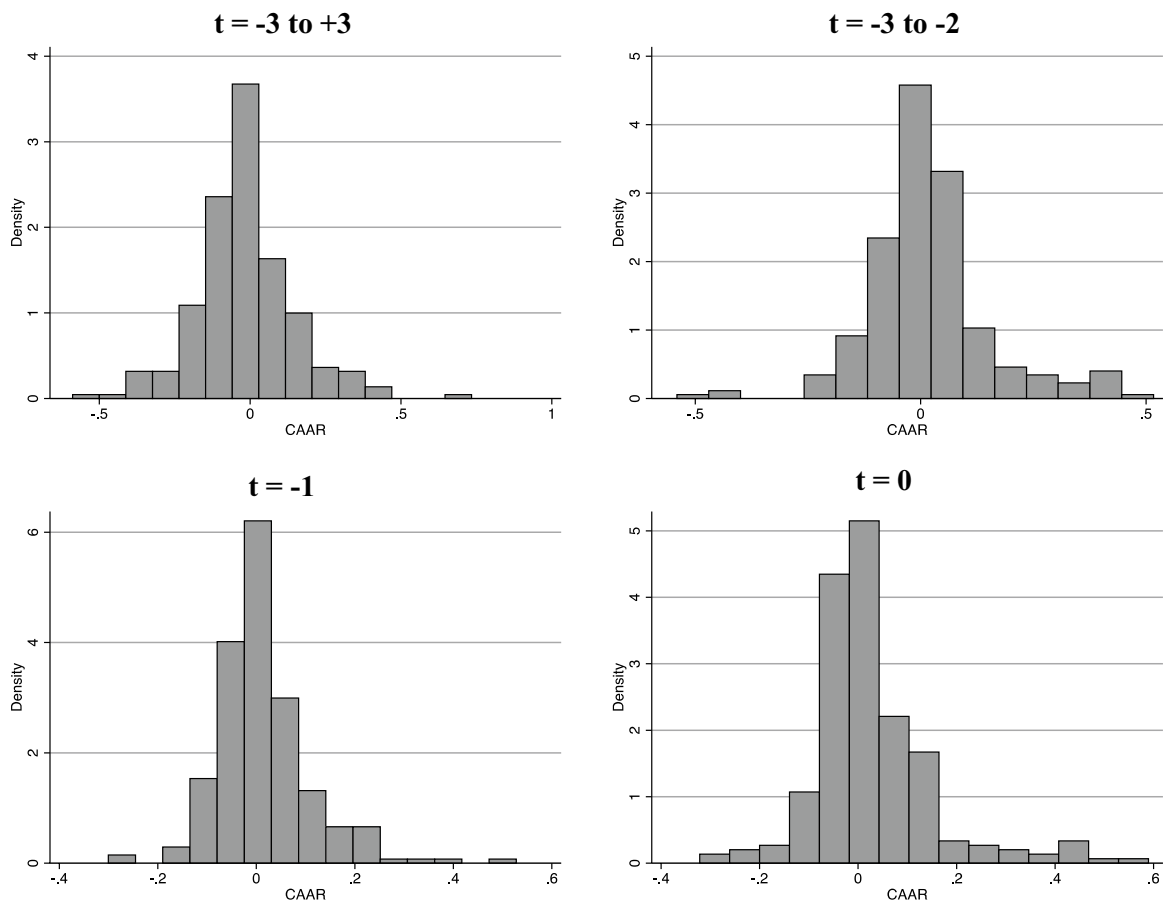

$$
\mathbf{t}=+\mathbf{1}
$$

$$
\mathbf{t}=+2 \text { to }+3
$$
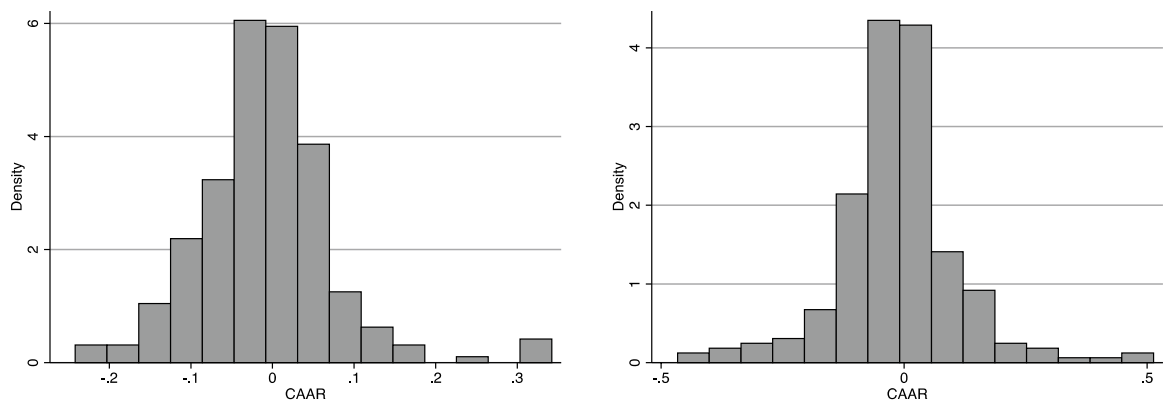

Fig. 3 CAAR distribution plots across different periods based on the market model $(N=250)$

Funding Open Access funding enabled and organized by Projekt DEAL.

\section{Declarations}

Conflict of interest The authors declare that they have no conflict of interest.

Open Access This article is licensed under a Creative Commons Attribution 4.0 International License, which permits use, sharing, adaptation, distribution and reproduction in any medium or format, as long as you give appropriate credit to the original author(s) and the source, provide a link to the Creative Commons licence, and indicate if changes were made. The images or other third party material in this article are included in the article's Creative Commons licence, unless indicated otherwise in a credit line to the 
material. If material is not included in the article's Creative Commons licence and your intended use is not permitted by statutory regulation or exceeds the permitted use, you will need to obtain permission directly from the copyright holder. To view a copy of this licence, visit http://creativecommons.org/licen ses/by/4.0/.

\section{References}

Aggarwal, R.K., Krigman, L., Womack, K.L.: Strategic IPO underpricing, information momentum, and lockup expiration selling. J. Financ. Econ. 66(1), 105-137 (2002). https://doi.org/10.1016/S0304405X(02)00152-6

Alameda Research. (2019). Investigation into the legitimacy of reported cryptocurrency exchange volume. https://ftx.com/volume-report-paper.pdf

Alexander, G.J., Janakiramanan, S.: International listings and stock returns: some empirical evidence. J. Financ. Quant. Anal. 23(2), 135-151 (1988). https://doi.org/10.2307/2330877

Amihud, Y., Mendelson, H., Pedersen, L.H.: Liquidity and asset prices. Found. Trends Finance (2005). https://doi.org/10.1561/0500000003

Ante, L.: Cryptocurrency, blockchain and crime. In: McCarthy, K. (ed.) The Money Laundering Market: Regulating the criminal economy, pp. 171-198. Agenda Publishing (2018). https://doi.org/10. 2307/j.ctv5cg8z1.10

Ante, L.: Market Reaction to Exchange Listings of Cryptocurrencies (2019). https://doi.org/10.13140/ RG.2.2.19924.76161

Ante, L., Sandner, P., Fiedler, I.: Blockchain-based ICOs: pure hype or the dawn of a new era of startup financing? J. Risk Financ. Manag. 11(4), 80 (2018). https://doi.org/10.3390/jrfm11040080

Ante, L., Fiedler, I., \& Strehle, E.: The influence of stablecoin issuances on cryptocurrency markets. Finance Res. Lett. (2020). https://doi.org/10.1016/j.frl.2020.101867

Ante, L.: Smart contracts on the blockchain-a bibliometric analysis and review. Telemat. Inf. (2020). https://doi.org/10.1016/j.tele.2020.101519

Baker, H.K., Nofsinger, J.R., Weaver, D.G.: International cross-listing and visibility. J. Financ. Quant. Anal. 37(3), 495-521 (2002)

Bancel, F., Mittoo, U.R.: European managerial perceptions of the net benefits of foreign stock listings. Eur. Financ. Manag. 7(2), 213-236 (2001)

Benedetti, H.: The economics of digital token cross-listings (2019). https://doi.org/10.2139/ssrn.3267392

Benedetti, H., Kostovetsky, L.: Digital tulips? Returns Invest. Initial Coin Off. (2018). https://doi.org/10. 2139/ssrn.3182169

Bitwise Asset Management.: Bitwise asset management - presentation to the U.S. securities and exchange commission (2019). https://www.sec.gov/comments/sr-nysearca-2019-01/srnysearca201901-51648 33-183434.pdf

Bouri, E., Roubaud, D., Shahzad, S.J.H.: Do Bitcoin and other cryptocurrencies jump together? Q. Rev. Econ. Finance 76, 396-409 (2020)

Bris, A., Cantale, S., Nishiotis, G.P.: A breakdown of the valuation effects of international cross-listing. Eur. Financ. Manag. 13(3), 498-530 (2007). https://doi.org/10.1111/j.1468-036X.2006.00370.x

Burnie, A.: Exploring the Interconnectedness of cryptocurrencies using correlation networks. In: The Cryptocurrency Research Conference 2018, pp. 1-29 (2018). http://arxiv.org/abs/1806.06632

Cantale, S.: The Choice of a Foreign Market as a Signal (1996)

Chowdhry, B., Nanda, V.: Multimarket trading and market liquidity. Rev. Financ. Stud. 4(3), 483-511 (1991)

Coffee, J.C.J.: Future as history: the prospects for global convergence in corporate governance and its implications. Northwest. Univ. Law Rev. 93(3), 641-708 (1999)

Coffee, J.C.J.: Racing towards the top: the impact of cross-listing and stock market competition on international corporate governance. Columbia Law Rev. 102(7), 1757-1831 (2002)

Dharan, B.G., Ikenberry, D.L.: The long-run negative drift of post-listing stock returns. J. Finance 50(5), 1547-1574 (1995)

Doidge, C., Karolyi, G.A., Stulz, R.M.: Why are foreign firms listed in the U.S. worth more? J. Financ. Econ. 71(2), 205-238 (2004) 
Errunza, V., Losq, E.: International asset pricing under mild segmentation : theory and test. J. Finance 40(1), 105-124 (1985)

Fanto, J.A., Karmel, R.S.: Companies regarding a U.S. listing. Stanf. J. Law Bus. Finance 51, 51-83 (1997)

Fisch, C., Meoli, M., Vismara, S.: Does blockchain technology democratize entrepreneurial finance? An empirical comparison of ICOs, venture capital, and REITs. Econ. Innov. New Technol. (2020). https://doi.org/10.1080/10438599.2020.1843991

Fisch, C., Momtaz, P.P.: Institutional investors and post-ICO performance: an empirical analysis of investor returns in initial coin offerings (ICOs). J. Corp. Finance 64, 101679 (2020)

Foerster, S.R., Karolyi, G.A.: The effects of market segmentation and investor recognition on asset prices: evidence from foreign stocks listing in the United States. J. Finance 54(3), 981-1013 (1999). https:// doi.org/10.1111/0022-1082.00134

Frésard, L., Salva, C.: The value of excess cash and corporate governance: evidence from US cross-listings. J. Financ. Econ. 98(2), 359-384 (2010). https://doi.org/10.1016/j.jfineco.2010.04.004

Gkillas, K., Bekiros, S., \& Siriopoulos, C.: Xtreme Correlation in Cryptocurrency Markets (2018). https://doi.org/10.2139/ssrn.3180934

Howe, J.S., Kelm, K.: The stock price impacts of overseas listings. Financ. Manag. 16(3), 51 (1987). https://doi.org/10.2307/3665980

Hu, A., Parlour, C.A., Rajan, U.: Cryptocurrencies: stylized facts on a new investible instrument. Financ. Manage. 48(4), 1049-1068 (2019). https://doi.org/10.1111/fima.12300

Jayaraman, N., Shastri, K., Tandon, K.: The impact of international cross listings on risk and return: the evidence from American depository receipts. J. Bank. Finance 17(1), 91-103 (1993). https://doi.org/ 10.1016/0378-4266(93)90081-n

Ji, Q., Bouri, E., Lau, C.K.M., Roubaud, D.: Dynamic connectedness and integration in cryptocurrency markets. Int. Rev. Financ. Anal. 63, 257-272 (2019)

McWilliams, A., Siegel, D.: Event studies in management research: theoretical and empirical issues. Acad. Manag. J. 40(3), 626-657 (1997)

Merton, R.C.: A simple model of capital market equilibrium with incomplete information. J. Finance 42(3), 483-510 (1987). https://doi.org/10.1111/j.1540-6261.1987.tb04565.x

Miller, D.P.: The market reaction to international cross-listings: evidence from depositary receipts. J. Financ. Econ. 51(1), 103-123 (1999). https://doi.org/10.1016/S0304-405X(98)00045-2

Miller, M.H., Rock, K.: Dividend policy under asymmetric information. J. Finance 40(4), 1031-1051 (1985)

Mittoo, U.R.: Managerial perceptions of the net benefits of foreign listing: Canadian evidence. J. Int. Financ. Manag. Acc. 4(1), 40-62 (1992). https://doi.org/10.1111/j.1467-646X.1992.tb00021.X

Momtaz, P.P.: Initial Coin Offerings (2019a). https://doi.org/10.2139/ssrn.3166709

Momtaz, P.P.: The pricing and performance of cryptocurrency. Eur. J. Finance (2019b). https://doi.org/ 10.1080/1351847x.2019.1647259

Nakamoto, S. (2008). Bitcoin : A Peer-to-Peer Electronic Cash System.

Pagano, M., Röell, A.A., Zechner, J.: The geography of equity listing: Why do companies list abroad? J. Finance 57(6), 2651-2694 (2002). https://doi.org/10.1111/1540-6261.00509

Roosenboom, P., Van Dijk, M.A.: The market reaction to cross-listings: Does the destination market matter? J. Bank. Finance 33(10), 1898-1908 (2009). https://doi.org/10.1016/j.jbankfin.2009.04.010

Silva, A.C., Chávez, G.A.: Cross-listing and liquidity in emerging market stocks. J. Bank. Finance 32(3), 420-433 (2008). https://doi.org/10.1016/j.jbankfin.2007.07.003

Spence, M.: Job market signaling. Q. J. Econ. 87(3), 355-374 (1973). https://doi.org/10. 1055/s-2004-820924

Troger, T.H.: Corporate governance in a viable market for secondary listing. Univ. Pennsylvania J. Bus. Employ. Law 10(2003), 89-185 (2007)

Warren, W., \& Bandeali, A.: 0x: An open protocol for decentralized exchange on the Ethereum blockchain (2017). https://doi.org/10.1007/s004649901080

You, L., Lucey, B.M., Shu, Y.: An empirical study of multiple direct international listings. Glob. Finance J. 24(1), 69-84 (2013). https://doi.org/10.1016/j.gfj.2013.03.004

Publisher's Note Springer Nature remains neutral with regard to jurisdictional claims in published maps and institutional affiliations. 